\title{
Editorial
}

\section{Is Innovation Interest Cyclical?}

\author{
João José Pinto Ferreira', Anne-Laure Mention², Marko Torkkeli
}

INESC TEC - INESC Technology and Science and FEUP - Faculty of Engineering, University of Porto, Portugal; 'RMIT University, Australia; ${ }^{L}$ Lappeenranta University of Technology, Finland;

jjpf@fe.up.pt, anne-laure.mentionermit.edu.au, marko.torkkeli@lut.fi

In the last issue of 2015, the editorial was titled "Winter is coming: The dawn of Innovation?" As almost 2 years have gone by, this topic was revisited. So why not wonder how innovation was going around this same time of the year? In trying to answer this question, a visit to Google $(\mathbb{C}$ Trends revealed an interesting and possibly unexpected chart that is illustrated in figure 1.

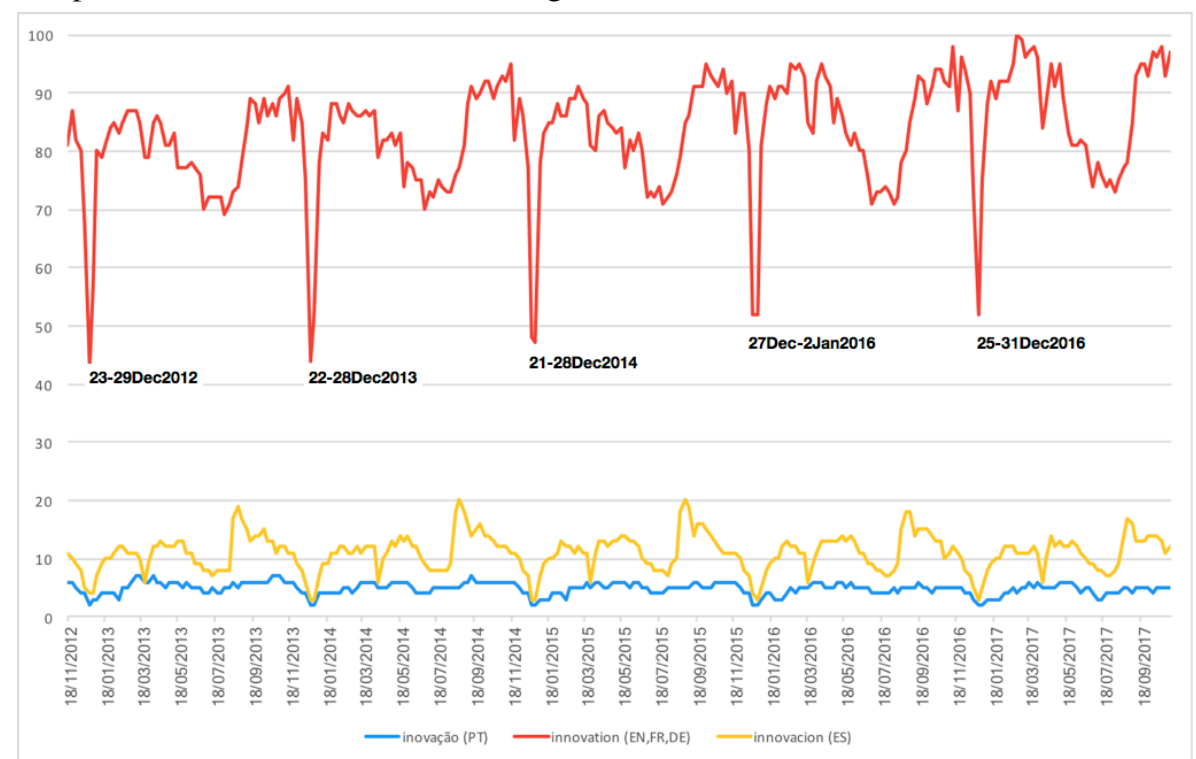

An improvement to the Data Collection System was applied from 01/01/16 (for all charts) In bold, inserted in the picture, the date periods corresponding to the lowest points on the chart.

Fig. 1. World interest along the time. Innovation $(E N, F R, D E)$, Innovacion (ES) and Inovação $(P T)$ as a search term in https://trends.google.com for the last five years. $100 \%$ translates a peak of popularity'.

1 Extracted from Google Trends explaining the contents of these charts: «The numbers represent the search interest relative to the highest point of the chart for a 
The world coverage for the chart in figure 1 is pictured in figure 2 where we can see that some regions covered by the search.

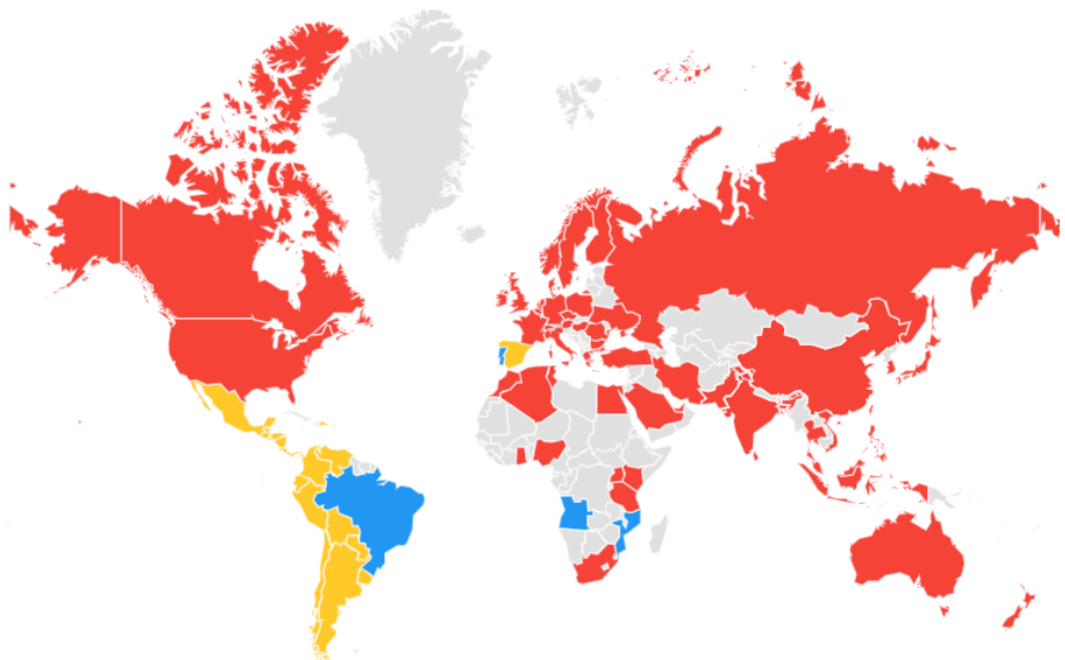

Fig. 2. Interest by region. Innovation (EN, FR, DE) - Red, Innovacion (ES) - Y ellow and Inovação $(P T)$ - Blue as a search terms in https://trends.google.com for the last five years.

Interestingly, this behavior looks very much periodic for these languages, with the lower point of popularity happening in the very few last days of each year or in the first days of the new year. These languages were selected as the four languages known by the authors listed in the report Languages for the Future - Which languages the UK needs most and why (2013).

A further detail from the search in figure 1, revealed that, for the English language, the users that looked-up the term Innovation, also searched for (top five out of 25):

$\begin{array}{lr}\text { technology innovation } & 100 \\ \text { business innovation } & 100 \\ \text { innovation center } & 95 \\ \text { management innovation } & 70 \\ \text { new innovation } & 70\end{array}$

where 100 means the most searched term and 50 means that the term was searched only $50 \%$ of the times.

The periodicity discovered in figure 1 led to a new search, this time only in English, with the words Innovation Management. Figure 3 pictures the results, again for the last 5 years, and a somehow periodic behavior may be observed as well.

region and the specified time interval. A value of 100 is the term's popularity peak. A value of 50 means the term has half the popularity. Likewise, an assessment of 0 means that the term had less than $1 \%$ of the popularity relative to the highest point. " 


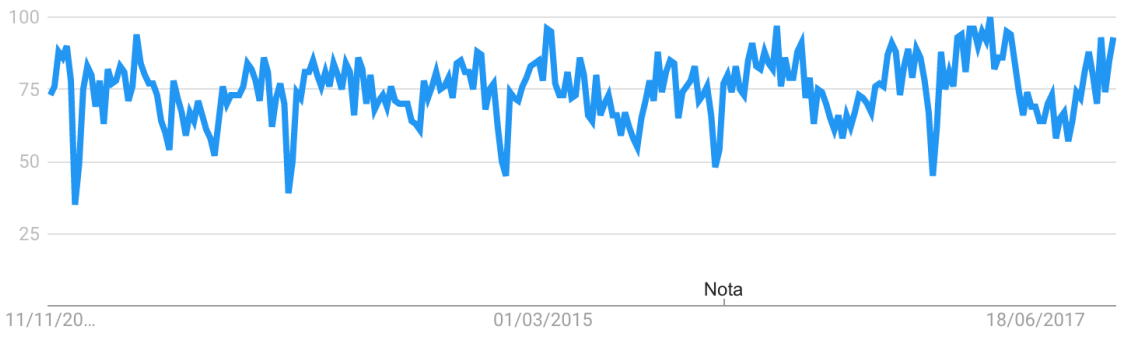

Fig. 3. World Interest along the time. Innovation Management as a search term in https://trends.google.com for the last five years. $100 \%$ translates a peak of popularity.

In face of this, one may wonder, is this happening for all keywords? A new test with the keyword Management revealed Figure 4. Again, we can see some periodicity but with smaller peaks, more stable, but with lower popularity happening again in the last few days of each year. Another search was performed using the word User Innovation and the results are illustrated in figure 5, which seem to reveal no particular periodic pattern as observed before.

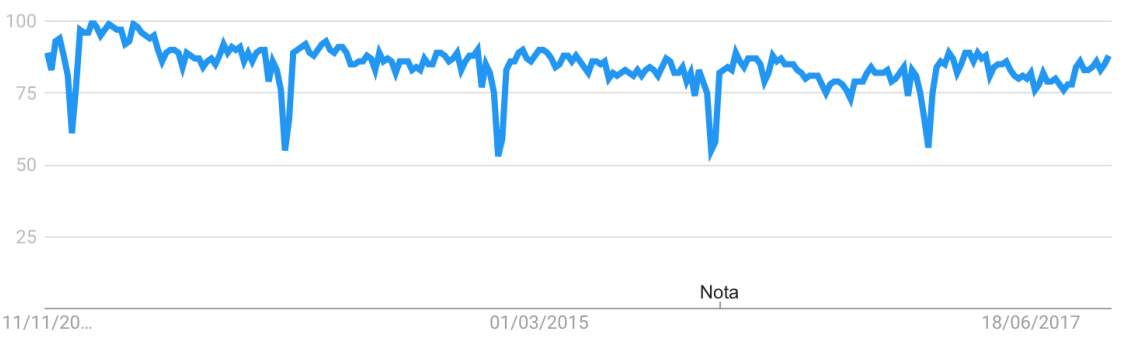

Fig. 4. World Interest along the time. Management as a search term in https://trends.google.com for the last five years. $100 \%$ translates a peak of popularity.

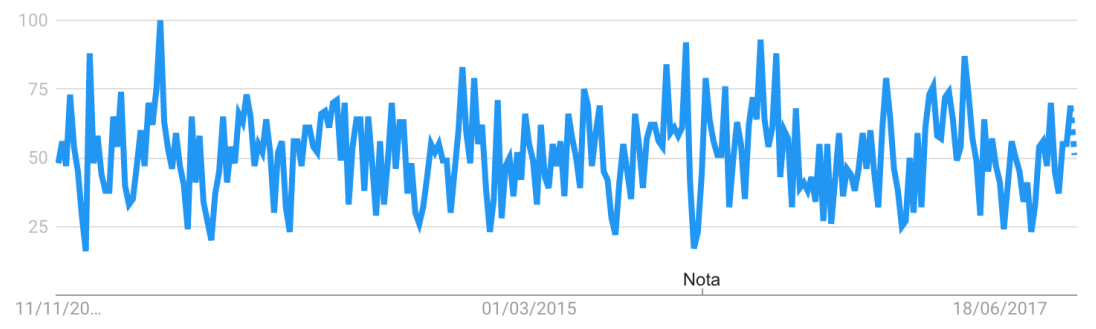

Fig. 5. World Interest along the time. User Innovation as a search term in https://trends.google.com for the last five years. $100 \%$ translates a peak of popularity.

It would be interesting to have an explanation for the observed behavior! One may wonder if a stronger popularity for the term Innovation just before the end of the year is related with companies preparing investments in innovation for the new year? Roughly, it is observed that the level of popularity starts going up from $75 \%$ by the end of August, then decreases just the days before the end of the year, and resumes in the new year to a similar level. This could be related to early stages of the project 
implementation in the new year, decreasing again (until June), possibly as those projects get to a more stable stage of development. For Innovation Management one may observe as well an increase and a decrease, similarly as seasonal as for Innovation.

But is there any value in exploring innovation through "web interest"? Shaughnessy and Vitalari (2011) picture quite an interesting analysis where, by looking into "the US-specific data, we can also see that the more future oriented term Open Innovation and the current in-vogue term Design Thinking are beginning to close on the very tools-based term TRIZ in the United States." Figure 6 illustrates how the chart introduced by those authors now unfolds for the US-Region, but now for the last four years. In 2011 these authors further said that "Over the last few years, we found interest in TRIZ is losing ground to the less formal open and design paradigms" and this seems to be confirmed by the increase of interest in Design Thinking. Again, we can picture the periodic behavior modulating this increasing interest trend. However, this behavior was not observed in Shaughnessy and Vitalari (2011).

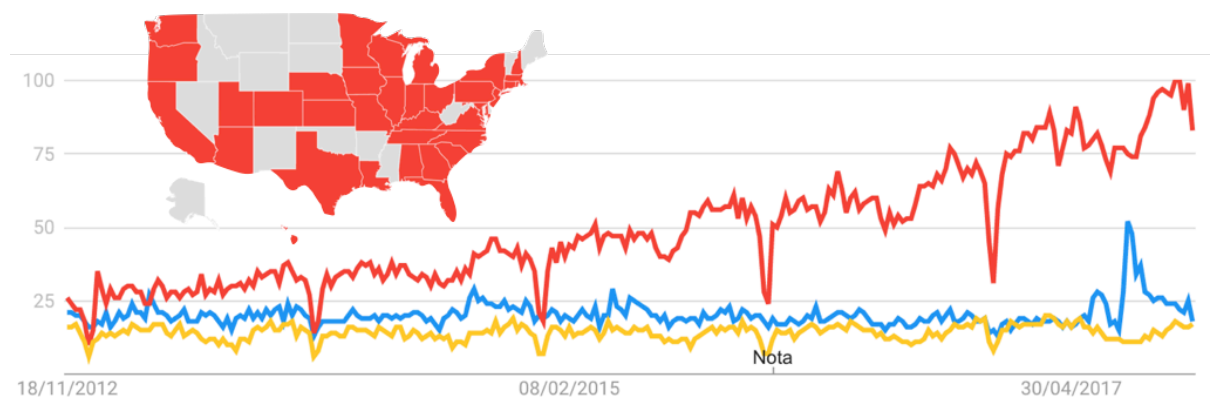

Fig. 6. World Interest along the time. TRIZ (blue) vs. Design Thinking (red) and Open Innovation (yellow) as a search terms in https://trends.google.com for the last five years. $100 \%$ translates a peak of popularity.

At this stage one would reasonably ask if there any research published specifically on the topic of innovation?

- A search in Scopus using (KEY (google AND trends) AND KEY (innovation)), reveals one paper, not directly related to the topic under discussion.

- A search in Scopus using (KEY (web AND interest) AND KEY (google AND trends)) revealed 4 papers, published in 2012, 2014, 2015 and 2017, with the following Author Keywords: Algal blooms; Biodiversity; Climate change; Data mining; Google Trends; Individual interest; Interest; Public opinion; Public perception and interest; Social Issue forecasting; Social media; Social network service; Social Networking Sites; Twitter; Web search trends; Web Trends Forecasting.

- A search in Scopus using (KEY (google AND trends) AND KEY (behaviour OR behavior)) revealed 35 papers. The analysis of author keywords in these 35 papers reveals 127 different keywords, and most of them with just one occurrence, only $10 \%$ had 2 or more occurrences. 
It seems that researchers from many different areas are exploiting the potential of these tools for their own topics of interest. We would argue that these tools will become increasingly popular in order to analyze web interest / trends and will likely be used to decision makers. As an example, it could be cited (Kristoufek, L., Moat, H. S., et al. 2016) stating that “(...) a greater number of searches for the term 'depression' is related to fewer suicides, whereas a greater number of searches for the term 'suicide' is related to more suicides", and further arguing that results reported in that paper show the "potential value of online communication data for creating new proxy measures of psychiatric illness across large populations". Although not strictly related to the study of innovation, this illustrates how exploring large populations through "web interest" may bring new perspectives into the system under observation. So what is Yours Web Interest!

Innovatively Yours,

João José Pinto Ferreira, Anne-Laure Mention, Marko Torkkeli

Editors

\section{References}

Kristoufek, L., Moat, H. S., \& Preis, T. (2016). Estimating suicide occurrence statistics using Google Trends. EPJ data science, 5(1), 32. DOI: https://doi.org/10.1140/epjds/s13688-016-0094-0

Languages for the Future - Which languages the UK needs most and why (2013) British Council, ISBN 978-0-86355-722-4

Shaughnessy H., Vitalari, N. (2011) The Global Innovation Interest Index. Harvard Business Review. Accessed October 2017. https://hbr.org/2011/06/the-globalinnovation-interest 